\section{The burden of disease of retinal vein occlusion: review of the literature}

\author{
Abstract \\ Retinal vein occlusion (RVO) is the second \\ most common cause of vision loss due \\ to retinal vascular disease. A literature \\ review was undertaken to understand the \\ epidemiology, clinical consequence, current \\ practice patterns, and cost of RVO. Pertinent \\ articles were identified by computerized \\ searches of the English language literature \\ in MEDLINE supplemented with electronic \\ and manual searches of society/association \\ proceedings and bibliographies of \\ electronically identified sources. Population- \\ based studies report a prevalence rate \\ of $\mathbf{0 . 5}-\mathbf{2 . 0 \%}$ for branch RVO and $0.1-0.2 \%$ \\ for central RVO. The 15-year incidence rate \\ is estimated to be $\mathbf{1 . 8 \%}$ for branch RVO and \\ $0.2 \%$ for central RVO. Patients with RVO \\ report lower vision-related quality of life \\ than those without ocular disease. Available \\ treatment options are limited. Until recently \\ there was no treatment for central RVO. \\ Laser photocoagulation is only recommended \\ for branch RVO in patients who have not \\ experienced severe vision loss. Emerging \\ evidence on the effectiveness of intravitreal \\ anti-vascular endothelial growth factor \\ therapy and dexamethasone intravitreal \\ implant is promising. Information on \\ the treatment patterns and cost of RVO is \\ extremely limited with one retrospective \\ analysis of secondary insurance payment \\ data identified and limited to the \\ United States population only. A better \\ understanding of the economic and \\ societal impact of RVO will help decision \\ makers evaluate emerging medical \\ interventions for this sight-threatening \\ disease. \\ Eye (2011) 25, 981-988; doi:10.1038/eye.2011.92; \\ published online 6 May 2011
}

M Laouri' ${ }^{1}$ E Chen ${ }^{1}$, M Looman ${ }^{1}$ and M Gallagher ${ }^{2}$

Keywords: retinal vein occlusion; epidemiology; cost; burden

Introduction

Retinal vein occlusion (RVO) is the second most common sight-threatening retinal vascular disorder after diabetic retinopathy. ${ }^{1} \mathrm{RVO}$ is an obstruction of the retinal venous system, and may involve the central retinal vein or a branch retinal vein. Possible causes are external compression or disease of the vein wall, for example, vasculitis. ${ }^{2}$ RVO can be divided into two primary categories, branch RVO (BRVO) and central RVO (CRVO), depending on the site of occlusion, with BRVO occurring more commonly than CRVO. ${ }^{2}$ CRVO may be further classified as ischemic, if there is significant enough pressure on the capillary system to result in areas without blood flow. If there are no areas of capillary non-perfusion, $\mathrm{CRVO}$ is considered to be non-ischemic.

Two recently published systematic reviews of the natural history of BRVO and CRVO concluded that untreated RVO results in vision impairment and significant ocular complications. ${ }^{1,3}$ Baseline visual acuity is moderately poor, ranging from $20 / 40$ to $<20 / 200$ in both BRVO and CRVO eyes. Although the visual acuity in untreated BRVO generally improves over time, it rarely improves beyond 20/40. ${ }^{1}$ The visual acuity in CRVO eyes typically decreases over time without treatment. ${ }^{3}$ About 5-15\% of eyes with BRVO develop macular edema over 1 year and the majority of patients with CRVO have signs of macular edema at presentation. Vitreous hemorrhage develops in about $40 \%$ of eyes with BRVO over an unspecified time period and in
${ }^{1}$ Health Economics and Outcomes, Quorum Consulting Inc., San Francisco, CA, USA

${ }^{2} \mathrm{HE} \& \mathrm{OR}$, Novartis Pharma AG, Basel, Switzerland

Correspondence: M Laouri, Health Economics and Outcomes, Quorum Consulting Inc., 180 Sansome Street, Tenth Floor, San Francisco,

CA 94104-3716, USA

Tel: + $14158350190 \times 127$;

Fax: + 14158350199

E-mail: Marianne.laouri@ quorumconsulting.com

Received: 8 December 2010 Accepted in revised form: 18 March 2011 Published online: 6 May 2011 
$10 \%$ of eyes with CRVO within 9 months of presentation. ${ }^{1,3}$

The findings from these reviews are helpful in guiding decisions regarding management of patients with RVO and in evaluating the efficacy and risk of new treatments in the context of the natural history of the disease.

However, to assess the need for new medical intervention, one needs to understand the prevalence and incidence of RVO and its subtypes, possible differences in demographic subgroups, how it is currently managed, as well as its economic impact on a national or regional healthcare system and the toll the disease places on the functioning of the individual and health-related quality of life (HRQoL). To our knowledge, a comprehensive review of the burden associated with RVO has not been performed to date. The purpose of this article is to summarize what is known about the burden associated with RVO and its subtypes worldwide, to determine any difference in burden across countries and distinct demographic subgroups, and to identify gaps in the literature that require further research.

\section{Patients and methods}

We conducted a comprehensive literature search in MEDLINE for articles related to the epidemiological, clinical, economic, and humanistic burden of RVO. Search terms included 'RVO', 'branch $\mathrm{RVO}^{\prime}$, and 'central $\mathrm{RVO}^{\prime}$, with the following terms 'prevalence', 'incidence', 'risk factors', 'epidemiology', 'treatment pattern', 'practice pattern', 'reimbursement', 'cost', 'economics', 'cost effectiveness', 'outcomes', 'visual impairment', 'vision loss', 'quality of life', 'utility', and 'registry'.
Articles were limited to those written in English and published between January 1990 and May 2010. After an initial abstract review, articles related to the burden of RVO were selected for full-text review.

In addition to the MEDLINE search, the publicly available abstracts from the Association for Research in Vision and Ophthalmology (ARVO) meetings were searched using the same terms as listed above. Treatment guidelines issued by the American Academy of Ophthalmologists, the International Council of Ophthalmology, the UK Royal College of Ophthalmologists, and the UK National Institute for Clinical Excellence websites were also searched for. Finally, we conducted a manual review of the bibliographies of full-text articles identified through MEDLINE for any additional references.

\section{Results}

The MEDLINE literature search generated 646 citations meeting the above criteria. On the basis of the review of article titles and abstracts, 85 articles were selected for full-text retrieval. After reviewing the full-text articles, 28 articles were included in the final review. Four supplemental full-text articles were identified through a manual bibliographic review. Four abstracts from ARVO were also included in this review along with two practice guidelines (Figure 1).

\section{Prevalence}

In addition to one pooled analysis of existing data, ${ }^{4}$ seven population-based studies that used retinal photographic grading for RVO diagnosis and distinguished RVO

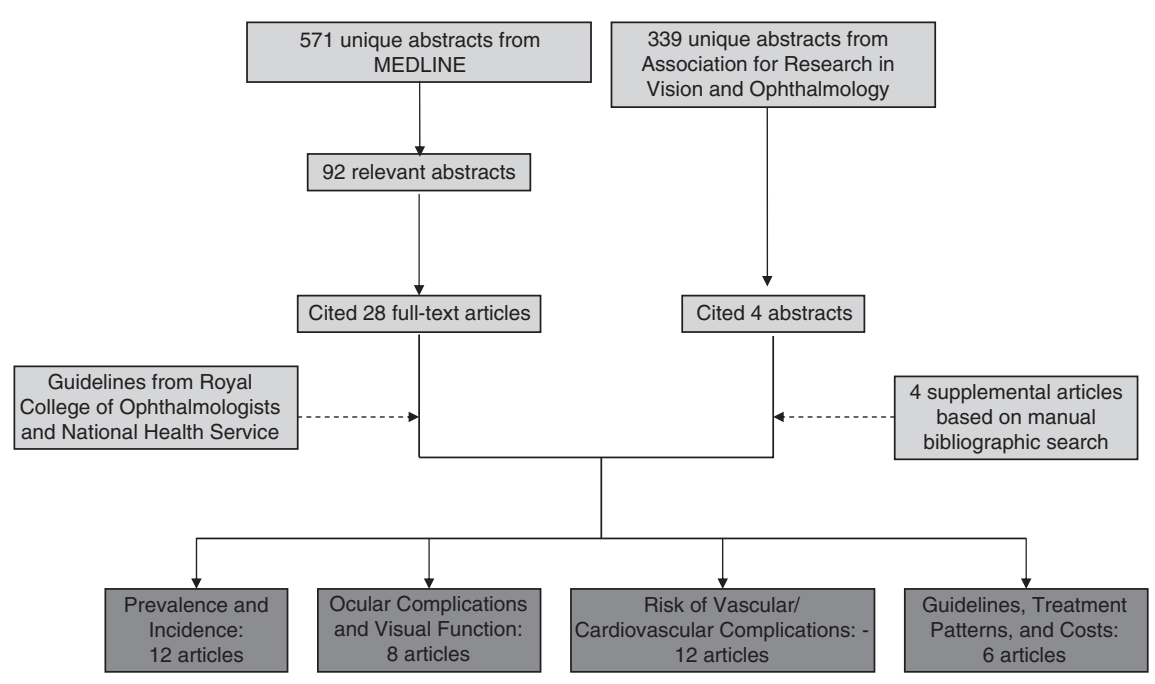

Figure 1 Schematic of literature selection. 
Table 1 Prevalence rates of retinal vein occlusion by country/region

\begin{tabular}{|c|c|c|c|c|c|c|c|c|c|c|}
\hline Region & Study & $\begin{array}{c}\text { Subjects, } \\
\mathrm{N}\end{array}$ & $\begin{array}{l}\text { Age } \\
\text { range, } \\
\text { year }\end{array}$ & $\begin{array}{l}\text { Eyes } \\
\text { per } \\
\text { subject }\end{array}$ & $\begin{array}{c}\text { Fields } \\
\text { per } \\
\text { eye }\end{array}$ & $\begin{array}{c}\text { Prevalence of } \\
\text { any } R V O, \% \\
(95 \% \mathrm{CI})\end{array}$ & $\begin{array}{c}\text { Prevalence } \\
\text { of BRVO,\% } \\
(95 \% \mathrm{CI})\end{array}$ & $\begin{array}{c}\text { Prevalence } \\
\text { of CRVO,\% } \\
(95 \% \mathrm{CI})\end{array}$ & $\begin{array}{c}\text { Ischemic } \\
\text { CRVO, \% } \\
(95 \% \text { CI })\end{array}$ & $\begin{array}{l}\text { Bilateral } \\
R V O, \%\end{array}$ \\
\hline Global & Rogers et $a l^{4}$ & 49869 & $\geq 30^{\mathrm{a}}$ & Both & $\geq 2$ & $0.52(0.44-0.60)$ & $0.44(0.37-0.52)$ & $0.08(0.06-0.10)$ & NR & NR \\
\hline Australia & Mitchell et $a l^{5}$ & 3654 & $\geq 49$ & Both & 6 & $1.6(1.3-1.9)$ & 1.1 (NR) & 0.5 (NR) & NR & 5.1 \\
\hline China & Liu et $a l^{6}$ & 4335 & $\geq 40$ & Both & 2 & $1.3(1.0-1.6)$ & $1.2(0.9-1.5)$ & $0.12(0-0.2)$ & $0.16(\mathrm{NR})^{\mathrm{b}}$ & 3.4 \\
\hline Europe $^{c}$ & Rogers et al ${ }^{4}$ & 4753 & $\geq 65$ & Both & 2 & 0.8 (NR) & 0.6 (NR) & 0.2 (NR) & NR & NR \\
\hline Japan & Yasuda et $a l^{7}$ & 1775 & $\geq 40$ & Both & 1 & 2.1 (NR) & 2.0 (NR) & 0.2 (NR) & NR & NR \\
\hline Netherlands & Rogers et $a l^{4}$ & 6418 & $\geq 55$ & Both & 2 & 0.6 (NR) & 0.5 (NR) & 0.1 (NR) & NR & NR \\
\hline Singapore & Lim $e t a l^{8}$ & 3265 & $40-80$ & Both & 2 & $0.7(0.4-1.0)$ & 0.6 (NR) & 0.2 (NR) & NR & 9.1 \\
\hline United States, BDES & Klein $e t a l^{9}$ & 4822 & $43-84$ & Both & 3 & 0.8 (NR) & $0.6(0.4-0.9)$ & $0.1(0-0.3)$ & NR & 0 \\
\hline United States, MESA & Cheung et $a l^{10}$ & 6147 & $45-84$ & Both & 2 & 1.1 (NR) & 0.9 (NR) & 0.2 (NR) & NR & 1.5 \\
\hline $\begin{array}{l}\text { United States, } \\
\text { ARIC + CHS }\end{array}$ & Wong et al ${ }^{11}$ & 15466 & $45-64$ & One & 2 & 0.3 (NR) & 0.2 (NR) & 0.04 (NR) & NR & NR \\
\hline
\end{tabular}

Abbreviations: ARIC, the Atherosclerosis Risk in Communities Study; BDES, the Beaver Dam Eye Study; BRVO, branch retinal vein occlusion; CHS, the Cardiovascular Health Study; CRVO, central retinal vein occlusion; MESA, the Multiethnic Study of Atherosclerosis; NR, not reported; RVO, retinal vein occlusion.

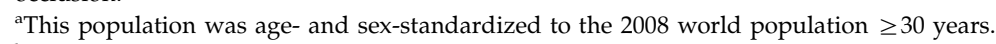

${ }^{\mathrm{b}}$ This figure was for ischemic BRVO or CRVO.

'The countries included in this study were Estonia, France, Greece, Italy, Northern Ireland, Norway, and Spain.

Table 2 Prevalence rates of retinal vein occlusion by age

\begin{tabular}{|c|c|c|c|c|c|c|c|c|c|c|c|c|c|}
\hline \multirow[t]{2}{*}{ Age, range } & \multirow{2}{*}{$\begin{array}{c}B M E S^{5} \\
R V O\end{array}$} & \multirow{2}{*}{$\begin{array}{l}B E S^{6} \\
R V O\end{array}$} & \multicolumn{3}{|c|}{ Hisayama $^{7}$} & \multirow{2}{*}{$\begin{array}{c}S M E S^{8} \\
R V O\end{array}$} & \multirow[t]{2}{*}{ Age Range } & \multicolumn{3}{|c|}{$B D E S^{9}$} & \multicolumn{3}{|c|}{$M E S A^{10}$} \\
\hline & & & $B R V O$ & CRVO & $R V O$ & & & $B R V O$ & $C R V O$ & $R V O$ & $B R V O$ & CRVO & $R V O$ \\
\hline $40-49$ & - & 0.3 & 0 & 0 & 0 & 0.1 & $<55$ & 0.2 & 0.1 & 0.3 & 0.3 & 0 & 0.3 \\
\hline 50-59 & 0.7 & 1.3 & 1.6 & 0 & 1.6 & 0.5 & $55-64$ & 0.3 & 0.1 & 0.4 & 1.1 & 0 & 1.1 \\
\hline $60-69$ & 1.2 & 2.1 & 2.7 & 0.5 & 3.2 & 1.2 & $65-74$ & 1.1 & 0.2 & 1.3 & 1.2 & 0.4 & 1.5 \\
\hline 70-79 & 2.1 & 2.8 & 2.3 & 0 & 2.3 & 1.0 & $\geq 75$ & 1.3 & 0.4 & 1.7 & 1.2 & 0.2 & 1.3 \\
\hline$\geq 80$ & 4.6 & & 4.6 & 0 & 4.6 & & & & & & & & \\
\hline
\end{tabular}

Abbreviations: BDES, the Beaver Dam Eye Study; BES, the Beijing Eye Study; BMES, the Blue Mountain Eye Study; BRVO, branch retinal vein occlusion; CRVO, central retinal vein occlusion; MESA, the Multiethnic Study of Atherosclerosis; SMES, the Singapore Malay Eye Study.

Age-specific data were not reported in BMES, BES, and SMES.

subtypes were identified (three from the United States, and one each from Australia, China, Japan, and Singapore).$^{5-11}$ Although prevalence data from European countries are not available in published reports, the investigators in the EUREYE and Rotterdam Eye study were contacted by Rogers et $a l^{4}$ and the data from these two studies were included in the pooled analysis and separately reported by Rogers et al. ${ }^{4}$

Overall, the prevalence of RVO appears to be fairly constant across all countries (Table 1). Globally, an estimated 16.4 million adults are affected by RVO (2.5 million by CRVO and 13.9 million by BRVO). ${ }^{4}$ The age and sex standardized prevalence is 5.20 (per 1000) for any RVO, 4.42 for BRVO, and 0.80 for CRVO in the population aged $\geq 30$ years. ${ }^{4}$

The prevalence of RVO in individual studies ranged from $0.3^{11}$ to $2.1 \%^{7}$ in populations older than 40 years, with the prevalence of RVO highest in Japan and Australia and lowest in Europe and Singapore (Table 1).
The low prevalence of RVO found in the Atherosclerosis Risk in Communities and Cardiovascular Health Studies ${ }^{11}$ is due to the fact that only one photograph of one eye was taken for each subject included in the study. In all studies, BRVO was more common than CRVO, ranging from $3^{8}$ to 10 times $^{6}$ more prevalent. Bilateral RVO is rare, affecting fewer than $10 \%$ of individuals with RVO (Table 1).

The prevalence of RVO is strongly associated with increasing age. RVO is rarely seen in individuals younger than 50 , but may affect up to $5 \%$ of individuals over the age of 80 (Table 2). The prevalence of RVO was similar between men and women in all studies that reported the prevalence by gender. Few studies compared the prevalence of RVO by race as most of these studies only enrolled subjects of one ethnic group. The only study to compare the prevalence of RVO in four ethnic groups (whites, blacks, Hispanics, and Chinese) found that the prevalence of RVO was similar across all groups 
$(P=0.76) .{ }^{10}$ In the pooled analysis of multinational studies, although prevalence was highest in Asians and Hispanics and lowest in whites, the overlapping confidence intervals suggest the differences were not statistically significant. ${ }^{4}$

\section{Incidence}

Few studies assessed the incidence of RVO and its subtypes. Three of the population-based studies that reported the prevalence of RVO also assessed the incidence: the Blue Mountains Eye Study, ${ }^{12}$ the Hisayama Study, $^{13}$ and the Beaver Dam Eye Study. ${ }^{9,14}$ In Australia, the 5-year incidence of any RVO was $1.0 \%$ and the 10-year incidence was $1.6 \% .^{12}$ These incidence rates were similar to the results found in the United States, where the 5-year incidence was $0.8 \%$ and the 15-year incidence was $2.3 \% .^{14}$ The 9-year incidence in Japan of $2.0 \%{ }^{13}$ is slightly higher than these findings.

The incidence of BRVO is generally higher than the incidence of CRVO. In the United States, the 5-year incidence of BRVO was $0.6 \%$ and the incidence of CRVO was $0.2 \%$; at 15 years the incidences were 1.8 and $0.5 \%$, respectively. ${ }^{9,14}$ In Australia, about three times as many individuals developed BRVO than CRVO over 10 years. ${ }^{12}$ The ratio of the incidence of BRVO to CRVO was much higher in Japan, where the 9-year incidences were 1.9 and $0.07 \%$, respectively. ${ }^{13}$ However, the small number of individuals that developed incident RVO in all these studies makes it difficult to know with accuracy the ratio of incident BRVO to incident CRVO and whether it varies among countries.

As with prevalence, the incidence of RVO increases with age. In Australia, individuals aged 70 years or older without RVO at baseline were more than three times as likely to develop RVO over 10 years than those younger than $60 .{ }^{12}$ In the United States, individuals over the age of 75 had about five times the rate of incident BRVO over 15 years as those between the ages of 43 and 54 years, though the incidence rates of CRVO for these two age groups were about the same. ${ }^{14}$ An analysis of secondary insurance payment data of outpatient and emergency department visits in Taiwan found that individuals aged $\geq 70$ years were about 12 times as likely to develop RVO than those between the ages of 40 and $49 .{ }^{15}$

\section{Ocular complications and visual function}

The natural history and clinical course of vision and ocular complications differ between BRVO and CRVO. In BRVO patients, the overall visual acuity is moderately poor at diagnosis, but visual acuity seems to improve over time without intervention, with between 37 and $74 \%$ of eyes with BRVO showing a two-line improvement. ${ }^{1}$
Though development of macular edema is common in BRVO eyes (5-15\% in 1 year), about $18-40 \%$ of cases with macular edema at baseline resolve over time. ${ }^{1}$ In CRVO cases, visual acuity at diagnosis is poor $(<20 / 40)$ and it decreases further over time. ${ }^{3}$ Compared with non-ischemic CRVO, ischemic CRVO is associated with lower mean visual acuity both at diagnosis and during the follow-up periods. Macular edema is frequently present at the time of CRVO diagnosis, which resolves in $\sim 30 \%$ of non-ischemic CRVO eyes and in up to $73 \%$ of ischemic CRVO eyes in 15 months. ${ }^{3}$ Neovascular glaucoma is much more likely to develop in ischemic CRVO than non-ischemic CRVO eyes. Up to $34 \%$ of eyes with non-ischemic CRVO convert to ischemic CRVO over 3 years. $^{3}$

Two United States studies assessed the impact of CRVO and unilateral BRVO on vision-related quality of life (VRQoL) using the National Eye Institute Visual Function Questionnaire with 25 questions (VFQ-25). ${ }^{16,17}$ CRVO was found to have a detrimental effect on VRQoL as study subjects scored significantly lower than a reference group without ocular disease and had similar scores to a cohort of patients with diabetic retinopathy. A subset of individuals with bilateral CRVO (10\%) had lower scores than the overall group, which were comparable with a population with low vision. ${ }^{16}$ The impact of unilateral BRVO appeared to be less than that of CRVO. These individuals also scored significantly lower than the group without ocular disease, but had significantly higher scores in nearly all subscales when compared with individuals with CRVO, low vision, age-related macular degeneration, and diabetic retinopathy. ${ }^{17}$

In both studies, analyses were performed to assess correlation between visual acuity in the worse-seeing or the better-seeing eye and VRQoL. Visual acuity in the worse-seeing eye was negatively correlated with VRQoL in individuals with unilateral BRVO for 9 of the 12 subscales but no correlations were found with visual acuity in the better-seeing eye. ${ }^{17}$ For both unilateral and bilateral CRVO, visual acuity in the worst-seeing eye was not found to predict VFQ-25 subscales, whereas worse visual acuity in the better-seeing eye, greater number of systemic medical conditions, and worse self-opinion about general health were strongly correlated with lower VFQ-25 responses. ${ }^{16}$ Owing to the significant impact of RVO on the quality of life of the patients, most patients are willing to undergo potentially invasive treatments. ${ }^{18}$ Evidence suggests that patients with vision loss due to macular edema following RVO report meaningful reduction in multiple dimensions of HRQoL measured by the short form 36 and NEI VFQ-25. ${ }^{19}$ Treatment of macular edema secondary to RVO by ranibizumab, however, has shown to improve the near and distance activities of the patients. ${ }^{20}$ Only one abstract reported 
utility values associated with visual acuity in retinal diseases, however, RVO-specific values were not reported. $^{21}$

\section{Risk of vascular and cardiovascular complications in RVO}

Patients with RVO have a higher prevalence of stroke $e^{5,22}$ and a greater risk of cardiovascular disease $\mathrm{e}^{23}$ than similarly aged individuals without RVO. However, a systematic review and two recent population-based studies in Taiwan suggest that RVO does not independently increase the risk of stroke or myocardial infarction. ${ }^{24-26}$ In the Annual Evidence Update on Retinal Vein Occlusion, the National Health Service in England concluded that there is insufficient evidence to confirm that RVO is a predictor of stroke. ${ }^{27}$

The evidence from observational studies on the impact of RVO on vascular mortality (ie, death from vascular causes) is conflicting. The Beaver Dam Eye Study showed participants with BRVO at baseline did not have an increased risk of mortality due to ischemic heart disease. ${ }^{9}$ Other population-based studies also showed that RVO did not predict cardiovascular ${ }^{26}$ or cerebrovascular mortality. ${ }^{28}$ Data from a pooled cohort of the Beaver Dam Eye Study and the Blue Mountain Eye Study showed no association between RVO and cardiovascular-related $(\mathrm{HR}=1.2 ; 95 \% \mathrm{CI}, 0.8-1.8)$ or cerebrovascular-related mortality ( $\mathrm{HR}=0.9 ; 95 \% \mathrm{CI}, 0.4-2.1)$ after adjustment for age, gender, body mass index, hypertension, diabetes, and other factors among patients of all ages. ${ }^{29}$ However, in RVO patients younger than 70 years, the risk of cardiovascular mortality was twice as high $(\mathrm{HR}=2.5$; 95\% CI, 1.2-5.2). ${ }^{29}$ A United Kingdom hospital-based study found that, compared with the general population, RVO patients had a higher rate of mortality related to myocardial infarction. ${ }^{30}$

Despite the documented association between RVO and systemic risk factors for cardiovascular diseases, RVO has not been shown to predict overall mortality. ${ }^{28,29,31}$

\section{Current treatment guidelines and emerging evidence}

At the time of this review, the only published treatment guidelines for RVO by the Royal College of Ophthalmologists (UK) referred to grid-pattern laser photocoagulation as the standard of care for macular edema secondary to BRVO following the 1984 Branch Vein Occlusion Study results, although patients with severe vision loss $(<6 / 60)$ and those in whom symptoms had been present for $>1$ year were unlikely to benefit from photocoagulation. ${ }^{2}$ There was no proven treatment for $\mathrm{CRVO}^{2}$ and randomized controlled trials failed to demonstrate visual acuity benefit from grid treatment.
During the last decade, a number of new treatments for the treatment of RVO complications have been investigated and strong evidence on their effectiveness has emerged. Recently, dexamethasone (Ozurdex, Allergan, Inc., Irvine, CA, USA) intravitreal implant was granted approval for the treatment of macular edema following BRVO or CRVO in the Unites States and the European Union based on two multicenter, doubleblind, randomized studies (GENEVA). ${ }^{32}$ Following dexamethasone, ranibizumab (Lucentis, Genentech, Inc., South San Francisco, CA, USA; Novartis Pharma AG, Basel, Switzerland) intravitreal injection was also approved in the United States for the same indication on the basis of two multicenter, randomized, doublemasked clinical trials (BRAVO and CRUISE). ${ }^{33,34}$ In these clinical trials, both dexamethasone and ranibizumab demonstrated clinically and statistically improved vision acuity compared with placebo. In GENEVA, 23 and $18 \%$ of patients with BRVO and CRVO, respectively, gained at least three lines (15 letters) of best-corrected visual acuity (BCVA) in the first 3 months after treatment with dexamethasone intravitreal implant, compared with 20 and $12 \%$ in the respective sham groups. ${ }^{32}$ In BRAVO and CRUISE, after 6 months of ranibizumab therapy, between 55 and $61 \%$ of patients with BRVO gained at least three lines of BCVA (compared with $28 \%$ in the sham group) and about $48 \%$ of patients with CRVO gained at least three lines of BCVA (compared with $17 \%$ in the sham group). ${ }^{33,34}$ Intravitreal triamcinolone acetonide has also been investigated and was shown to be superior to observation in CRVO but failed to demonstrate superiority in efficacy or safety over grid photocoagulation in BRVO in a multicenter phase III SCORE study. ${ }^{35,36}$ Although this article was under review, the Royal College of Ophthalmologists' guidelines were updated to recommend consideration of dexamethasone intravitreal implant and ranibizumab for managing macular edema following CRVO and BRVO. ${ }^{37}$

\section{Patterns of care and economic burden}

Information on treatment patterns and the economic burden associated with RVO is sparse. Except one study that examined the total direct medical costs for patients with RVO in an elderly population in the United States, ${ }^{38}$ no evidence exists with respect to direct medical costs from the non-United States markets, direct non-medical costs, or indirect medical costs attributable to RVO.

Treatment patterns outside of the United States have not been studied, underscoring a gap in the literature on the economic burden related to RVO.

Fekrat et $a l^{38}$ performed a retrospective cohort study of a nationally representative sample of Medicare 


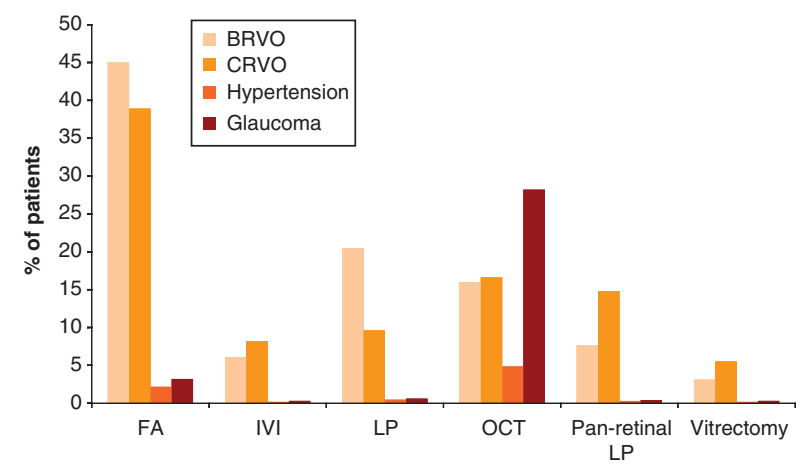

Figure 2 The 1-year resource use associated with retinal vein occlusion. Source, Fekrat et al. ${ }^{38}$ BRVO, branch retinal vein occlusion; CRVO, central retinal vein occlusion; FA, fluorescein angiography; IVI, intravitreal injection; LP, laser photocoagulation; OCT, optical coherence tomography. In all, $6 \%$ of patients in the hypertension cohort had other retinal disease which required use of OCT.

beneficiaries in the United States from 2001 to 2006 using secondary insurance payment data. The authors estimated the 1-year and 3-year costs for BRVO and CRVO patients and compared them with the costs for individuals with hypertension and glaucoma (which are risk factors for RVO) without RVO. The 1-year resource use for BRVO and CRVO patients compared with hypertension and glaucoma patients is presented in Figure 2.

Except for optical coherence tomography, significantly more BRVO and CRVO patients received imaging services and treatments than the controls. Use of fluorescein angiography and optical coherence tomography increased from 2001 to 2005. The use of intravitreal injections increased from $<1 \%$ in both BRVO and CRVO patients to $>13 \%$ in BRVO patients and $16 \%$ in CRVO patients. On the contrary, use of laser photocoagulation remained relatively flat for BRVO patients and decreased for CRVO patients. ${ }^{38}$

A comparison of direct medical costs measured by total medicare reimbursement amounts adjusted for baseline suggests that BRVO patients had 16\% higher 1-year costs and 12\% higher 3-year costs than hypertension patients. Compared with glaucoma patients, BRVO patients incurred $18 \%$ higher costs at 1 year and $13 \%$ higher costs at 3 years. ${ }^{38}$ CRVO patients had 22 and 15\% higher costs at 1 and 3 years, respectively, than hypertension patients, and 24 and $16 \%$ higher costs compared with glaucoma patients at 1 and 3 years (Figure 3 ) ${ }^{38}$ Inpatient costs accounted for $\sim 40 \%$ of total costs at 1 and 3 years in all groups. Costs in the year before RVO onset were nearly 30\% lower for BRVO patients (\$7211 vs \$10153) and 24\% lower for CRVO patients (\$8851 vs \$11587) than in the index year. ${ }^{38}$ On the

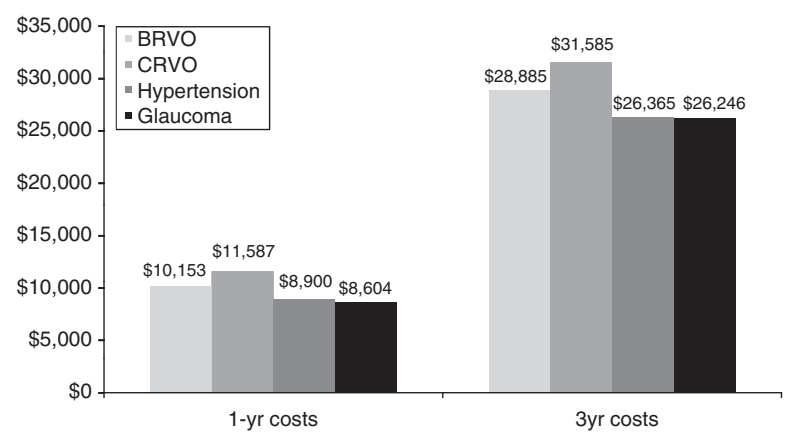

Figure 3 The 1-year and 3-year costs associated with retinal vein occlusion compared with hypertension and glaucoma. Source, Fekrat et al. ${ }^{38}$ BRVO, branch retinal vein occlusion; CRVO, central retinal vein occlusion.

basis of this study and the prevalence of RVO from the Beaver Dam Eye Study, the estimated annual direct costs related to managing United States Medicare population with RVO were expected to reach $\$ 5.8$ billion dollars in 2006 ( $\$ 4.5$ billion and $\$ 1.3$ billion for BRVO and CRVO, respectively). It is worth noting that costs incurred by non-Medicare payers, patients, and caregivers were not included and the proportion of the total costs attributable to ophthalmology care was not reported. Only one cost-effectiveness study was identified from the review. Brown et al ${ }^{39}$ evaluated the incremental cost effectiveness of laser photocoagulation for vision loss associated with BRVO. A decision analysis with Markov modeling was performed incorporating efficacy data from the BVOS and patient-based preferences from time trade-off utility analysis. The study suggested that laser photocoagulation was associated with an incremental cost of \$6118 (2000 US\$) for an additional qualityadjusted life year in the base case with a range of $\$ 3370$ to $\$ 19299$ in the sensitivity analysis during a patient's lifetime.

\section{Conclusion}

This literature review summarizes the evidence pertaining to the epidemiological, clinical, economic, and humanistic burden of RVO. A sizable body of literature on the epidemiology and natural history of RVO has emerged, however, little is known about the financial burden associated with RVO on patients, caregivers, and the healthcare system. The evidence to confirm that RVO is a predictor of stroke or cardiovascular complications is insufficient. As the population ages, the burden of RVO is likely to increase, in light of the emerging diagnostic tests and therapies for RVO, a better understanding of the economics of identifying and managing sight-threatening complications related to RVO is crucial. 


\section{Conflict of interest}

The sponsor (Novartis Pharma AG) participated in the study design and manuscript and approval, but did not assist with the literature search or review, synthesis, and interpretation of results. ML, EC, and ML are consultants for and received funding for this research from Novartis.

\section{Acknowledgements}

This study was supported by Novartis Pharma AG, Basel, Switzerland.

\section{References}

1 Rogers SL, McIntosh RL, Lim L, Mitchell P, Cheung N, Kowalski JW et al. Natural history of branch retinal vein occlusion: an evidence-based systematic review. Ophthalmology 2010; 117(6): 1094-1101.

2 The Royal College of Ophthalmologists. Interim guidelines for management of retinal vein occlusion. 2009. Available at:http:/ / www.rcophth.ac.uk. Accessed June 2010.

3 McIntosh RL, Rogers SL, Lim L, Cheung N, Wang JJ, Mitchell $\mathrm{P}$ et al. Natural history of central retinal vein occlusion: an evidence-based systematic review. Ophthalmology 2010; 117(6): 1113-1123.

4 Rogers S, McIntosh RL, Cheung N, Lim L, Wang JJ, Mitchell P et al. The prevalence of retinal vein occlusion: pooled data from population studies from the United States, Europe, Asia, and Australia. Ophthalmology 2010; 117(2): 313-319.

5 Mitchell P, Smith W, Chang A. Prevalence and associations of retinal vein occlusion in Australia. The Blue Mountains Eye Study. Arch Ophthalmol 1996; 114(10): 1243-1247.

6 Liu W, Xu L, Jonas JB. Vein occlusion in Chinese subjects. Ophthalmology 2007; 114(9): 1795-1796.

7 Yasuda M, Kiyohara Y, Arakawa S, Hata Y, Yonemoto K, Doi $Y$ et al. Prevalence and systemic risk factors for retinal vein occlusion in a general Japanese population: the Hisayama study. Invest Ophthalmol Vis Sci 2010; 51(6): 3205-3209.

8 Lim LL, Cheung N, Wang JJ, Islam FM, Mitchell P, Saw SM et al. Prevalence and risk factors of retinal vein occlusion in an Asian population. Br J Ophthalmol 2008; 92(10): 1316-1319.

9 Klein R, Klein BE, Moss SE, Meuer SM. The epidemiology of retinal vein occlusion: the Beaver Dam Eye Study. Trans Am Ophthalmol Soc 2000; 98: 133-141.

10 Cheung N, Klein R, Wang JJ, Cotch MF, Islam AF, Klein BE et al. Traditional and novel cardiovascular risk factors for retinal vein occlusion: the multiethnic study of atherosclerosis. Invest Ophthalmol Vis Sci 2008; 49(10): 4297-4302.

11 Wong TY, Larsen EK, Klein R, Mitchell P, Couper DJ, Klein BE et al. Cardiovascular risk factors for retinal vein occlusion and arteriolar emboli: the Atherosclerosis Risk in Communities \& Cardiovascular Health studies. Ophthalmology 2005; 112(4): 540-547.

12 Cugati S, Wang JJ, Rochtchina E, Mitchell P. Ten-year incidence of retinal vein occlusion in an older population: the Blue Mountains Eye Study. Arch Ophthalmol 2006; 124(5): 726-732.
13 Arakawa S, Yasuda M, Kiyohara Y, Hata Y, Ishibashi T. Nine-year incidence and risk factors for retinal vein occlusion in a general Japanese population: the Hisayama Study. Invest Ophthalmol Vis Sci 2009; 50, E-abstract 3727.

14 Klein R, Moss SE, Meuer SM, Klein BE. The 15-year cumulative incidence of retinal vein occlusion: the Beaver Dam Eye Study. Arch Ophthalmol 2008; 126(4): 513-518.

15 Ho JD, Tsai CY, Liou SW, Tsai RJ, Lin HC. Seasonal variations in the occurrence of retinal vein occlusion: a five-year nationwide population-based study from Taiwan. Am J Ophthalmol 2008; 145(4): 722-728.

16 Deramo VA, Cox TA, Syed AB, Lee PP, Fekrat S. Visionrelated quality of life in people with central retinal vein occlusion using the 25-item National Eye Institute Visual Function Questionnaire. Arch Ophthalmol 2003; 121(9): 1297-1302.

17 Awdeh RM, Elsing SH, Deramo VA, Stinnett S, Lee PP, Fekrat $S$. Vision-related quality of life in persons with unilateral branch retinal vein occlusion using the 25-item National Eye Institute Visual Function Questionnaire. $\mathrm{Br}$ J Ophthalmol 2010; 94(3): 319-323.

18 Chang MA, Fine HF, Bass E, Bressler SB, Schachat AP, Solomon SD et al. Patients' preferences in choosing therapy for retinal vein occlusions. Retina 2007; 27(6): 789-797.

19 Rentz AM, Kowalski J, Revicki D, Loewenstein A, Blumenkranz MS, Yoon Y et al. Normative comparison of generic- and vision-targeted health-related quality of life (HRQL) outcomes in patients with vision loss due to macular edema following retinal vein occlusion. Invest Ophthalmol Vis Sci 2010; 51, E-abstract 4728.

20 Varma R, Bressler NM, Suner IJ, Lee P, Dolan CM, Ward J et al. Ranibizumab improves patient-reported near and distance vision activities in patients with macular edema following retinal vein occlusion. Invest Ophthalmol Vis Sci 2010; 51, E-abstract 5212.

21 Hornberger JC, Shewade A, Doberne JW, Kowalski J, Nguyen H. A systematic literature review of utilities associated with visual acuity in retinal diseases. Invest Ophthalmol Vis Sci 2008; 49, E-abstract 4478.

22 Hayreh SS, Zimmerman B, McCarthy MJ, Podhajsky P. Systemic diseases associated with various types of retinal vein occlusion. Am J Ophthalmol 2001; 131(1): 61-77.

23 Martin SC, Butcher A, Martin N, Farmer J, Dobson PM, Bartlett WA et al. Cardiovascular risk assessment in patients with retinal vein occlusion. Br J Ophthalmol 2002; 86(7): 774-776.

24 Doubal FN, Hokke PE, Wardlaw JM. Retinal microvascular abnormalities and stroke: a systematic review. J Neurol Neurosurg Psychiatry 2009; 80(2): 158-165.

25 Ho JD, Liou SW, Lin HC. Retinal vein occlusion and the risk of stroke development: a five-year follow-up study. Am J Ophthalmol 2009; 147(2): 283-290.

$26 \mathrm{Hu}$ CC, Ho JD, Lin HC. Retinal vein occlusion and the risk of acute myocardial infarction (correction of infraction): a 3-year follow-up study. Br J Ophthalmol 2009; 93(6): 717-720.

27 National Health Service. 2010 Annual Evidence Update on Retinal Vein Occlusion: cardiovascular morbidity and mortality associated with retinal vein occlusion. Available at http://www.library.nhs.uk/eyes. Accessed June 2010.

28 Mansour AM, Walsh JB, Henkind P. Mortality and morbidity in patients with central retinal vein occlusion. Ophthalmologica 1992; 204(4): 199-203.

29 Cugati S, Wang JJ, Knudtson MD, Rochtchina E, Klein R, Klein $\mathrm{BE}$ et al. Retinal vein occlusion and vascular mortality: 
pooled data analysis of 2 population-based cohorts. Ophthalmology 2007; 114(3): 520-524.

30 Tsaloumas MD, Kirwan J, Vinall H, O'Leary MB, Prior P, Kritzinger EE et al. Nine year follow-up study of morbidity and mortality in retinal vein occlusion. Eye (Lond) 2000; 14(Part 6): 821-827.

31 Christoffersen N, Gade E, Knudsen L, Juel K, Larsen M. Mortality in patients with branch retinal vein occlusion. Ophthalmology 2007; 114(6): 1186-1189.

32 Haller JA, Bandello F, Belfort Jr R, Blumenkranz MS, Gillies M, Heier J et al. Randomized, sham-controlled trial of dexamethasone intravitreal implant in patients with macular edema due to retinal vein occlusion. Ophthalmology 2010; 117(6): 1134.e3-1146.e3.

33 Brown DM, Campochiaro PA, Singh RP, Li Z, Gray S, Saroj $\mathrm{N}$ et al. Ranibizumab for macular edema following central retinal vein occlusion six-month primary end point results of a phase III study. Ophthalmology 2010; 117(6): 1124.e1-1133.e1.

34 Campochiaro PA, Heier JS, Feiner L, Gray S, Saroj N, Rundle AC et al. Ranibizumab for macular edema Following branch retinal vein occlusion six-month primary end point results of a phase III study. Ophthalmology 2010; 117(6): 1102.e1-1112.e1.

35 Ip MS, Scott IU, VanVeldhuisen PC, Oden NL, Blodi BA, Fisher $\mathrm{M}$ et al. A randomized trial comparing the efficacy and safety of intravitreal triamcinolone with observation to treat vision loss associated with macular edema secondary to central retinal vein occlusion: the Standard Care vs Corticosteroid for Retinal Vein Occlusion (SCORE) study report 5. Arch Ophthalmol 2009; 127(9): 1101-1114.

36 Scott IU, Ip MS, VanVeldhuisen PC, Oden NL, Blodi BA, Fisher $\mathrm{M}$ et al. A randomized trial comparing the efficacy and safety of intravitreal triamcinolone with standard care to treat vision loss associated with macular Edema secondary to branch retinal vein occlusion: the Standard Care vs Corticosteroid for Retinal Vein Occlusion (SCORE) study report 6. Arch Ophthalmol 2009; 127(9): 1115-1128.

37 The Royal College of Ophthalmologists. Interim guidelines for management of retinal vein occlusion. 2010. Available at http://www.rcophth.ac.uk. Accessed March 2011.

38 Fekrat S, Shea AM, Hammill BG, Nguyen H, Kowalski JW, Schulman KA et al. Resource use and costs of branch and central retinal vein occlusion in the elderly. Curr Med Res Opin 2010; 26(1): 223-230.

39 Brown GC, Brown MM, Sharma S, Busbee B, Brown H. Incremental cost-effectiveness of laser therapy for visual loss secondary to branch retinal vein occlusion. Ophthalmic Epidemiol 2002; 9(1): 1-10. 